\title{
IMPlicaÇões Éticas do efeito Mateus Na CiÊnCia
}

\author{
Adriana Silva Barbosa ${ }^{1}$
}

\begin{abstract}
Resumo
O efeito Mateus é um fenômeno social que reforça a estrutura de classes da ciência. Esse artigo tem como objetivo analisar as implicações éticas do efeito Mateus na ciência, entendendo que este possui implicações éticas positivas e negativas. As implicações éticas positivas centram-se no contexto individual, beneficiando poucos indivíduos, enquanto as implicações éticas negativas focam-se na coletividade por meio do ofuscamento de cientistas talentosos, inclusive daqueles enquadrados nas minorias sociais, e do desconhecimento e/ou falta de reconhecimento por seus trabalhados científicos. Disso se depreende que as implicações éticas do efeito Mateus resultam em reforço de preconceitos e exclusões sociais no âmbito da ciência e podem influenciar negativamente no avanço no conhecimento científico.
\end{abstract}

Palavras-chave: Efeito Mateus, ética, ciência, sistema de recompensas

\section{Ethical implications of The Matthew EFFECT IN SCIENCE}

\begin{abstract}
The Matthew effect is a social phenomenon that reinforces the structure of classes in Science. This paper aims to analyze the ethical implications of the Matthew effect in Science, which has positive and negative ethical implications. The positive ethical implications focus on the individual context, benefiting few individuals, while the negative ethical implications focus on the community, through overshadowing talented scientists, including those framed in social minorities and, ignoring and/or lacking of recognition their scientific works. It means that the ethical implications of the Matthew effect result in reinforcement of prejudice and social exclusion in the context of science and may negatively influence the advance of scientific knowledge.
\end{abstract}

1 Bióloga. Doutoranda em Política Científica e Tecnológica pela Universidade Estadual de Campinas (Unicamp), Brasil. drybarbosa@yahoo.com.br 
Key-words: Matthew effect, ethic, science, rewards system

\section{INTRODUÇÃo}

Este artigo tem como objeto de estudo as implicações éticas do efeito Mateus, enunciado por Robert K. Merton (MERTON, 1977a), na ciência, uma vez que esta encontra-se sujeita aos mesmos fenômenos que a sociedade.

A ciência é uma atividade social humana, organizada e institucionalizada que se desenvolve de maneira sistematizada no intuito de gerar novos conhecimentos, exigindo, portanto, dos cientistas disposições de caráter moral de modo amplo para que possam executar eficazmente suas tarefas (CUPANI, 1998). Disto se depreende que o caráter social do conhecimento científico tem se tornado uma parte cada vez mais preponderante das discussões sobre o papel da ciência no mundo (LIMA, 1994); uma vez que ela é ambivalente por ser um conhecimento vivo que, ao mesmo tempo, pode libertar ou subjugar, dependendo do uso que fazemos dela (MORIN, 2005).

Este aspecto traz a necessidade do constante reexame do sistema de valores da ciência sob a luz da ética, bem como indica que a ética deve estar profundamente entrelaçada a todos os aspectos do fazer científico, o que demanda o estudo do sistema de recompensas da ciência e dos fenômenos a ele relacionados. Um fenômeno comum neste sistema é o "efeito Mateus", no qual os pesquisadores mais célebres tendem a receber mais reconhecimento e recursos financeiros por suas atividades acadêmicas, enquanto os pesquisadores pouco conhecidos tendem a receber pouco ou nenhum reconhecimento por suas atividades (MERTON, 1977a), tal como dito no capítulo 25, versículo 29, do livro de São Mateus: "Porque a todo o que tem, darse-lhe-á, e terá em abundância; mas ao que não tem, até aquilo que tem ser-lhe-á tirado". 
Embora os estudos de Robert Merton sobre o ethos da ciência - complexo de valores e normas, com ressonância afetiva que deve ser obrigatório para os cientistas (MERTON, 1979) - tenham sido realizados na primeira metade do século $X X$, muitos de seus aspectos ainda continuam relevantes no presente, dentre os quais o efeito Mateus, uma vez que as agências de fomento à pesquisa e os órgãos de formação de recursos humanos de nível superior têm cobrado o incremento da produção científica, notadamente de artigos científicos.

A quantidade de publicações científicas de um país pode ser um indicativo de seu avanço científico e tecnológico, o qual contribui para seu desenvolvimento econômico e, portanto, para seu destaque mundial, fazendo com que os pesquisadores entrem numa corrida para aumentar sua produção científica, evidenciando ainda mais o efeito Mateus, pois alguns pesquisadores adquirem maior destaque, enquanto muitos outros permanecem obscurecidos. A patente atualidade deste fenômeno tem gerado uma série de questionamentos na comunidade científica, muitos dos quais referentes ao sistema de recompensas da produtividade científica (ROCHA, et al., 2012), que tende a centralizar o reconhecimento acadêmico em pesquisadores mais produtivos (MERTON, 1977a).

Assim, torna-se relevante estudar as implicações éticas do efeito Mateus na Ciência, uma vez que o mesmo interfere na dinâmica de produções científicas dos pesquisadores, afetando suas vidas acadêmicas, bem como o status de suas instituições. Para tanto, elaborou-se a seguinte questão norteadora: quais as implicações éticas do efeito Mateus na ciência? Assim, este artigo tem como objetivo analisar essas implicações. 


\section{Metodologia}

Este artigo caracteriza-se como uma revisão crítica de literatura, de caráter qualitativo, realizado por meio de pesquisas nas bases de dados Google Acadêmico, SciELO, Portal Capes e Bireme, durante o período de fevereiro a junho de 2014, empregando como descritores os seguintes termos: Robert Merton e ética, produção científica e ética, financiamento científico e efeito Mateus, financiamento científico e efeito Mateus e ética, efecto Mateo en la Ciência, the Matthew effect, the Matthew effect and ethic, ética individual, ética individualista, ética e o papel do cientista, participação feminina na ciência, ética e ciência, preconceito e ciência. Alguns termos de busca foram empregados nos idiomas espanhol e/ou inglês, pois foram encontrados poucos ou nenhum resultado com o uso do idioma português.

Durante as buscas em bases de dados, foram coletados 71 artigos científicos a partir da leitura do título e resumo. Destes, 16 foram utilizados para compor o escopo teórico deste trabalho, pois atendiam aos seguintes critérios: tratar do sistema de valores da ciência expresso por Robert Merton e/ou de suas ideias sobre a ciência, tratar sobre o efeito Mateus e/ou sobre produção científica, abordar a produção científica, tratar sobre ética e/ou da relação entre ética e ciência, versar sobre o preconceito na ciência e/ou sobre a participação feminina na ciência. Foram também utilizados livros que contém ensaios escritos por Robert Merton e por outros autores, os quais se mostraram relevantes para a elaboração deste artigo.

Como este artigo científico propõe-se a analisar as implicações éticas do efeito Mateus na ciência, será desenvolvido em três eixos: "Efeito Mateus na ciência: implicações éticas positivas", "Efeito Mateus na ciência: implicações éticas negativas" e "Reflexões sobre as implicações éticas do efeito Mateus na ciência". 


\section{Efeito Mateus na CiênCia: IMPLiCações Éticas POSItivas}

A socialização dos cientistas é uma experiência intensa e prolongada, que é reforçada e suplementada pela prática de trocar informação por reconhecimento, produzindo assim cientistas que aderem fortemente aos valores da ciência que, por sua vez, são reforçados pelas recompensas conseguidas pelos cientistas. Todavia, embora esse reconhecimento seja muito importante para os cientistas, a maioria deles nega que este seja um incentivo para a realização de suas pesquisas, afirmando que o fazem desinteressadamente quando, na verdade, a recusa em admitir a importância do reconhecimento serve para dar realce à universalidade dos padrões científicos; pois, ao publicar os resultados de seus trabalhos, o cientista dirige-se a todos os colegas possíveis em todas as épocas possíveis (HAGSTROM, 1974).

O desejo de reconhecimento social faz com que os cientistas conformem-se com as normas científicas, contribuindo com as suas descobertas para toda a comunidade, mas eles aprendem a contar com a injustiça devido à atribuição não-equitativa de recompensas (HAGSTROM, 1974), que leva ao reforço do status de uns cientistas e a supressão do status de outros, caracterizando, assim, o efeito Mateus (MERTON, 1977a). Todavia, é importante lembrar que almejar reconhecimento por seus feitos não é agir imoralmente, mas em função de um interesse pessoal que favorece o ego (PEGORARO, 2002), uma vez é natural do ser humano querer ser reconhecido e/ou homenageado e isso não é diferente na comunidade científica.

Segundo Merton(1977a), a ciênciaéum sistema de comunicação no qual o efeito Mateus possui implicações disfuncionais para as carreiras dos cientistas que sofrem seus efeitos nas primeiras etapas de seu desenvolvimento, sendo, portanto, uma pauta social funcional para certos aspectos do sistema científico e disfuncional para certos indivíduos do sistema. 
Disso se depreende que o efeito Mateus na ciência se dá por mecanismos de memória e seleção (BUNGE, 2002), que envolvem processos de decisão, o momento de selecionar os parâmetros de medida em cada âmbito e processos perceptivos individuais (RODRÍGUEZ, 2009), apresentando, portanto, implicações negativas e positivas. Estas últimas são individualistas, afetam um grupo pequeno de cientistas e instituições e lembram o que acontece na sociedade em que uma elite detém a maior parte dos privilégios e da renda gerada. Portanto, o efeito Mateus reproduz, em menor medida, a estratificação existente na sociedade. Merton (1938) relata que o sistema de recompensas traduz a estratificação social existente na ciência, distribui-se à medida que os cientistas são reconhecidos por meio do julgamento de seus pares e é essencial para estabilização de suas carreiras profissionais.

Neste contexto, a noção de comunidade científica torna-se central na obra de Merton, favorecendo a discussão das condições da estrutura social que permite a constituição da ciência como uma instituição específica e dotada de legitimidade na sociedade. Portanto, a ciência é entendida como um fenômeno social, que se relaciona com a cultura em sentido amplo. Isso significa que as ações do cientista não devem ser entendidas apenas como as de alguém que planeja seu comportamento buscando atender seus próprios interesses, mas também como as de alguém cujas atitudes respondem à estrutura institucional que legitima um sistema de valores que permitem que elas ocorram (KROPF E LIMA, 1998-1999).

As implicações positivas do efeito Mateus centram-se numa pequena parcela da comunidade científica: cientistas reconhecidos filiados a instituições renomadas e pesquisadores iniciantes ligados a estes cientistas. De acordo com Merton (1977a e 1988), os cientistas reconhecidos são carismáticos, têm mais facilidade de publicar seus trabalhos, que sempre são considerados relevantes para a ciência. Devido à grande visibilidade e credibilidade que possuem, conseguem 
mais financiamento para suas pesquisas e geralmente recebem todo o crédito pelas publicações que levam seus nomes, mesmo que sua participação seja mínima. Isso significa queestes cientistas reconhecidos tendem a se tornar ainda mais reconhecidos e a impulsionar cada vez mais o desenvolvimento científico de sua equipe de pesquisa e da instituição em que trabalham, atraindo sempre mais prêmios e financiamentos.

Estudos como o de Cole e Cole (1967), realizado na comunidade norte-americana de físicos da década de 1960, reforçam o efeito Mateus ao apontarem a existência de uma correlação positiva entre o número de citações e a qualidade da pesquisa, uma vez que os pesquisadores mais citados são geralmente os mais reconhecidos. De acordo com Latour (2011), a relevância das citações para o reconhecimento dos pesquisadores e para o desenvolvimento da própria ciência é tão grande que o importante mesmo para o cientista é ter seu artigo citado, mesmo que a citação seja feita no intuito de questionar seu trabalho de pesquisa; pois, para um resultado de pesquisa transformar-se em fato, ele precisa ser lido e citado. Isso significa que um dos maiores problemas da produção científica é interessar alguém para ser citada; já que tudo o que um cientista fez com os artigos que utilizou (corroborou as ideias de alguns e contestou as ideias de outros) para elaborar seu artigo, precisa ser feito também com sua publicação. Do contrário, o cientista e seu artigo serão esquecidos e seu trabalho de pesquisa não se constituirá num fato científico.

Sob esta ótica, é vantajoso para os cientistas iniciantes fazer parte das equipes de pesquisa dos cientistas reconhecidos; pois eles beneficiam-se dessa experiência ao utilizarem-se dos financiamentos conseguidos pelos cientistas reconhecidos, ao publicarem seus artigos científicos mais facilmente (já que estes contam com o nome do cientista reconhecido) e incrementarem a possibilidade de seus trabalhos serem citados por seus parese, de um dia, também alcançarem reconhecimento 
(MERTON, 1977a e 1988). Além disso, outra clara manifestação do efeito Mateus na ciência é o fato de que universidades e institutos de pesquisas sediados em grandes centros urbanos possuem maior visibilidade, pesquisadores mais reconhecidos e mais financiamento para pesquisa.

Merton (1988) relata que o efeito Mateus está presente também no início da vida acadêmica de muitos pesquisadores que, ao entrar na universidade, inicialmente se destacam e são agraciados com bolsas de estudo, que os estimulam ao aprimoramento e ao crescimento acadêmico no intuito de tornarem-se futuros cientistas renomados.

O próprio Merton foi beneficiado pelo efeito Mateus; pois é considerado o pai da moderna sociologia da ciência e, apesar de ter escrito vários trabalhos em colaboração com outros cientistas, costuma-se recordar apenas seu nome e atribuir-lhe todo o mérito, o qual se consubstanciou na criação da cátedra Robert K. Merton na Universidade de Colúmbia, por ocasião de seu aniversário de 80 anos (BUNGE, 2002). Além disso, Merton também é conhecido por ter sido o primeiro a empregar o conceito de efeito Mateus na Ciência (RODRÍGUEZ, 2009).

A importância atribuída ao sistema de publicações científicas norte-americano também pode ser considerada um exemplo do efeito Mateus. Publicar em periódicos norte-americanos faz com que os pesquisadores adquiram mais visibilidade junto à comunidade científica, pois os artigos publicados nestes periódicos são mais lidos, citados e possuem maior pontuação em baremas de concursos e progressão de carreira, além de um fator de impacto mais elevado nos índices de pontuação/avaliação de publicações científicas. Devese ressaltar também que o sistema de publicações científicas norteamericano possui seus próprios indicadores bibliométricos como o Web of Science que, de acordo com o Portal de Periódicos Capes (CAPES, 2014), engloba os índices das bases Science Citation Index 
Expanded (SCI-EXPANDED), Social Sciences Citation Index (SSCI), Arts $\mathcal{E}$ Humanities Citation Index (A\&HCI), Conference Proceedings Citation Index-Science (CPCI-S) e Conference Proceedings Citation Index - Social Science \& Humanities (CPCI-SSH).

Além disso, em todas as áreas do conhecimento, existem periódicos norte-americanos de renome internacional, que adquirem cada vez mais prestígio, pois costumam publicar resultados de pesquisas consideradas de ponta, realizadas por pesquisadores também reconhecidos internacionalmente, tais como os agraciados com o prêmio Nobel ou que concorreram a ele. Nesta conjuntura, todos os pesquisadores almejam publicar seus artigos científicos nos periódicos no sistema de publicações científicas norte-americano para angariar destaque internacional e impulsionar suas carreiras acadêmicas.

Assim, percebe-se que as implicações positivas do efeito Mateus concentram-se, predominantemente, no campo da ética individual, resultante da ética clássica, voltada para o indivíduo, que é aquele que não é dividido (indivisum), que é uno e distinto de todas as outras coisas. Nesta perspectiva, a consciência moral sugere que se aceite os valores da sociedade e os promova (PEGORARO, 2002). Além disso, a tradição puritana considera a liberdade individual e a prosperidade material como sinal de aprovação divina para a qual o verdadeiro sucesso é inseparável da criação de uma comunidade de homens livres, fundada em valores éticos (MacDOWELL, 1990). Depreende-se, então, que a essência do espírito da ciência moderna é a ética puritana que combinou em si o racionalismo e o empirismo e proporcionou um acordo entre o puritanismo e o temperamento científico (MERTON, 1977b), embora Ben-David e Sullivan (1975) alertem que deve haver uma distinção entre o surgimento da ciência moderna como um novo tipo de teoria científica e a emergência da institucionalização da ciência. 
Sob este ponto de vista, o efeito Mateus pode ser considerado ético; pois, segundo Bunge (1972), os sistemas éticos conhecidos ajustam-se às convenções vigentes em grupos sociais limitados. Além disso, o efeito Mateus pode ser encarado como um sinal de prosperidade material e imaterial, configurando-se como a expressão e a promoção dos valores da comunidade científica que, por sua vez, reproduz os valores da sociedade; já que, de acordo com Rodríguez (2009), o efeito Mateus não se restringe à ciência, mas está presente em vários segmentos da sociedade com distintas denominações de mesmo significado: efeito Halo, efeito riqueza, efeito dinheiro chama dinheiro e efeito bola de neve.

Neste sentido, Rodríguez (2009) resume os benefícios individuais do efeito Mateus como materiais (econômicos, prêmios e outros recursos) e imateriais (privilégios, considerações, poder e fama), os quais têm o máximo de valor em função de um determinado parâmetro considerado relevante para a comunidade científica e/ ou sociedade, situando os cientistas beneficiados em uma posição privilegiada, de primeiro lugar, numa determinada categoria nos âmbitos local, regional, nacional ou global por serem considerados os melhores, que são, consequentemente, os mais beneficiados e supervalorizados, eclipsando os que estão ao redor.

É importante mencionar que, ainda que indiretamente, o efeito Mateus pode trazer implicações éticas positivas à sociedade; pois os resultados das pesquisas de cientistas renomados ou premiados são mais amplamente lidos, divulgados e podem ser mais facilmente aplicados em benefício da coletividade, devido ao destaque que obtêm junto à comunidade científica e à sociedade, inclusive por meio de comunicações não científicas e de fácil entendimento ao público leigo, tais como reportagens em jornais e revistas de cultura geral, telejornais e websites de notícias e/ou interesse geral. Este último aspecto é corroborado pelo próprio Merton (1977a) que afirma que tanto a 
autoimagem como a imagem pública dos cientistas são modeladas em grande parte pelo testemunho comunalmente convalidado por outros cientistas importantes de que estão a altura dos exigentes requisitos de sua área do conhecimento.

\section{Efeito Mateus Na CiÊnCia: IMPlicações Éticas Negativas}

Ao contrário das implicações éticas positivas, as implicações éticas negativas do efeito Mateus na ciência são de ordem coletiva, atingindo uma grande parcela da comunidade científica; pois, de acordo com Merton (1977a), o meio científico é estratificado socialmente, sendo construído tanto por cientistas reconhecidos ou não. Disso decorre que um grande número de cientistas não premiados tem contribuído com o desenvolvimento da ciência tanto ou mais do que os cientistas premiados.

Neste contexto, o efeito Mateus interfere negativamente no desenvolvimento da carreira de muitos cientistas talentosos e desconhecidos que nunca chegam a receber o devido mérito por seus trabalhos e são simplesmente esquecidos como se eles e seu trabalho nunca tivessem existido, corroborando a afirmação de Latour (2011) sobre a necessidade de citação para que os resultados de uma pesquisa se tornem, de fato, científicos. Todavia, há cientistas que, desconhecidos e/ou ignorados em vida, são reconhecidos anos após sua morte, quando seus feitos científicos são reconhecidos pela comunidade científica, tais como Waterson e Mendel (MERTON, 1977a e 1988), dentre outros.

Além disso, preconceitos sociais referentes a gênero, origem étnica e condição financeira são reproduzidos pelo efeito Mateus; uma vez que estas características, se consideradas desfavoráveis, podem dificultar o reconhecimento científico. Rosalind Franklin é um dos exemplos deste preconceito, pois não recebeu o reconhecimento 
merecido por suas contribuições para a elucidação da dupla hélice do DNA (Ácido Desoxirribonucleico). De acordo com Rezende (2009), ao escrever o livro "The Double Helix" em 1968, Watson admitiu o uso de dados e fotografias não publicados de Rosalind Franklin sem sua autorização e conhecimento. Além disso, Hayashi et al.(2007), relata que ela era vítima de preconceito por ser mulher e judia no King's College de Londres, uma instituição anglicana e tradicionalmente masculina. Oliveira $(2009$, p.7) relata a discriminação vivenciada por ela:

No King's College (Londres), onde Rosalind Franklin trabalhava, não havia banheiro para mulheres. Ao reclamar, passou a ser considerada uma "excêntrica", da qual todos queriam se livrar. Wilkins, que chefiava o laboratório, dizia que era muito azar que logo ele tivesse que trabalhar com uma feminista! A "ocultação" do seu trabalho e nome como codescobridora da dupla hélice demonstra o machismo predominante no mundo da ciência (OLIVEIRA, 2009, p. 7).

Ainda no que concerne à influência do gênero sob o reconhecimento científico, é interessante lembrar o caso de Harriet Zuckerman, segunda esposa e colaboradora de Merton. Embora seja uma cientista reconhecida, é notável que, apesar de ter desenvolvido vários estudos que serviram como referência para que Merton escrevesse seus famosos artigos sobre o sistema de recompensas na ciência e sobre o efeito Mateus, sua importância é, muitas vezes, eclipsada pela fama de Merton, o qual reconheceu sua dívida para com ela anos depois em seu artigo "O Efeito Mateus II" (MERTON, 1988). Para as mulheres, dar-se-ia, então, um efeito inverso ao efeito Mateus, o efeito Matilda, que foi assim nomeado por Rossiter (1993) em homenagem a Matilda Joslyn Gage (1826-1898), uma americana feminista, sufragista, crítica da religião e da Bíblia que, no século XIX, foi uma das primeiras sociólogas do conhecimento a vislumbrar 
e lamentar as injustiças científicas contra as mulheres; as quais ela própria experimentou.

Outro aspecto digno de nota é o fato de que os cientistas iniciantes e/ou não reconhecidos são menos citados e, portanto, não são considerados referência, mesmo que seu trabalho seja melhor e mais inovador do que o de cientistas reconhecidos. Este aspecto negativo do efeito Mateus também pode contribuir para que os cientistas desconhecidos e/ou iniciantes tenham dificuldades para conseguir financiamento para suas pesquisas, pois este geralmente está atrelado a um barema com uma série de critérios relacionados à obtenção de títulos de pós-graduação, quantidade e idade da produção científica, recebimento de prêmios e outras formas de reconhecimento científico. Essa supervalorização de títulos de pós-graduação é exemplificada por Merton (1988) ao relatar que o famoso biólogo Haldane contou ao seu biógrafo Ronald Clark (CLARK, 1969) que teve um talentoso pupilo indiano que realizou importantes pesquisas que proporcionaram o aumento da produtividade do arroz na Índia; mas não recebeu nenhum crédito por ser um pesquisador iniciante, desconhecido e desprovido de títulos de pós-graduação. Assim, todo o crédito pela pesquisa ficou com Haldane que já era um pesquisador renomado.

Neste contexto, é importante salientar que o conhecimento, o talento e a capacidade de pesquisa nem sempre estão atrelados a títulos. Nas ciências naturais, onde se realiza pesquisas em laboratório, não é raro encontrar alunos de iniciação científica que possuem mais facilidade para aplicar e melhorar as técnicas de pesquisas do que seus orientadores com título de doutorado; mas o mérito costuma ser sempre dado ao orientador. Além disso, deve-se registrar que, embora existam cursos de graduação em nível de bacharelado em que o graduado é habilitado para trabalhar em laboratório, realizando pesquisas e emitindo laudos, no Brasil, o status de pesquisador é 
conferido apenas a quem tem o título de doutor e grande parte dos editais de financiamento exigem que os concorrentes sejam doutores.

Disso se depreende que, se nos primórdios do desenvolvimento da ciência era preciso ser autodidata, na atualidade, é cada vez mais difícil sê-lo; pois, em muitas áreas do conhecimento, as pesquisas são cada vez mais complexas, demandandolaboratórios com equipamentos cada vez mais caros e, para um pesquisador desconhecido e/ou iniciante conseguir uma infraestrutura adequada para realizar suas pesquisas, precisa aliar-se a um pesquisador renomado que assume oficialmente a responsabilidade e ganha os créditos pelos resultados da pesquisa. Nas ciências sociais e humanas, embora não seja necessária a montagem de laboratórios com equipamentos caros, os critérios de titulação e reconhecimento empregados para a obtenção de financiamento para a pesquisa são os mesmos que os dados às ciências naturais.

Nesta conjuntura, torna-se necessário lembrar que Machado de Assis, considerado um dos maiores escritores brasileiros e com destaque internacional, era mulato, gago e estudou apenas até a quarta série primária. Cora Coralina, uma das mais brilhantes poetisas brasileiras, era uma doceira que também estudou até a quarta série primária. Joaquim Barbosa, ministro aposentado do Supremo Tribunal Federal, é um exemplo atual de pessoa de origem humilde que conseguiu sobrepujar o efeito Mateus e obteve reconhecimento por seu talento. Mas quantas outras pessoas, homens e mulheres, não conseguiram sobrepujá-lo e foram lançados ao esquecimento, apesar de suas importantes contribuições para a ciência e/ou sociedade?

Ainda no contexto do início da vida acadêmica, alguns estudantes são considerados talentos precoces, ganham bolsa de estudos e outros estímulos para continuar na carreira acadêmica, enquanto outros não apresentam um destaque inicial, não recebem os mesmos estímulos; mas tardiamente, quando já foram privados de muitas oportunidades, mostram grandes potencialidades que podem 
nunca chegar a se realizar. Este aspecto leva à supressão inadvertida de talento e tem consequências negativas para o avanço coletivo do conhecimento e para justiça distributiva (MERTON, 1988). Além disso, os alunos talentosos que não possuem bolsa são menos valorizados, pois tem que conciliar seus estudos e pesquisa com trabalho, encontram mais dificuldades para frequentar eventos científicos, divulgar suas pesquisas e custear a elaboração de seus trabalhos de conclusão de curso (seja ele uma monografia, uma dissertação ou tese) e são desfavorecidos pelos baremas que fornecem uma menor pontuação para os bolsistas voluntários, desmerecendo seu talento e esforço não remunerado.

O efeito Mateus não se restringe apenas aos cientistas, mas abrange também as instituições. Instituições renomadas geralmente possuem mais destaque nacional (às vezes, até destaque internacional), possuemestruturafísica maioremaisequipada, têm maiorcredibilidade e visibilidade, recebem mais financiamento e concentram os cientistas renomados; enquanto os cientistas talentosos e desconhecidos costumam trabalhar em instituições também desconhecidas e, muitas vezes, tem que se conformar com financiamentos menores para suas pesquisas. Merton (1988) corrobora este pensamento ao afirmar que, por possuírem mais financiamento, as instituições de elite fazem com que os cientistas talentosos vinculados a elas ampliem mais precocemente seu potencial de adquirir vantagens diferencialmente cumulativas. Portanto, o sistema de recompensas, a alocação de recursos e outros sistemas de seleção social criam e mantêm uma estrutura de classes na ciência ao proporcionar uma distribuição estratificada de trabalho científico significativo entre os cientistas, já que as instituições mais financiadas e prestigiosas atraem os estudantes mais promissores, concentram e mantêm os cientistas mais premiados e considerados excelentes (MERTON, 1988). Isso significa que ambos, pesquisador renomado e instituição de prestígio, trabalham no intuito de reforçar 
seu duplo padrão de excelência; uma vez que "o espaço das relações no campo científico não é homogêneo, sendo detectáveis estreitas relações entre o lugar que os indivíduos ocupam, as redes sociais a que pertencem e os resultados de pesquisa que produzem" (ÁVILA, 1997, p.17).

Além disso, em caso de descoberta simultânea, fruto de trabalhos independentes realizados por pesquisadores renomados e pesquisadores desconhecidos, o cientista reconhecido tende a levar mais crédito pela descoberta e a ser mais citado por ela. Este aspecto é uma clara evidência do efeito Mateus e de sua capacidade de afetar a visibilidade do número de vezes em que se realiza e se publica independentemente um descobrimento e da posição ocupada pelos cientistas descobridores dentro do sistema de estratificação da ciência (MERTON, 1977a).

Ainda no que concerne à publicação de resultados de pesquisa, o processo de revisão por pares de artigos submetidos à publicação também pode sofrer a influência do efeito Mateus, privilegiando a publicação de artigos de cientistas famosos em detrimento de artigos de cientistas desconhecidos. Segundo Davyt e Velho (2000), este aspecto faz com que este sistema de apreciação de artigos seja considerado por muitos como fechado e tendencioso devido à possibilidade de desvios em favor de cientistas reconhecidos de universidades prestigiadas e de redes elitistas de old boys (pesquisadores com visões semelhantes à área de pesquisa do avaliador, colegas, amigos), os quais desfavoreceriam grupos de pesquisadores jovens, de minorias étnicas, mulheres, pesquisadores de instituições menos conhecidas, etc. Percebe-se, então, que um texto não deve ser considerado bom apenas se é escrito por alguém famoso e que um autor merece fama se escreve bons textos (BUNGE, 2002).

Deve-se mencionar também que, na atualidade, vive-se num ambiente de intensa concorrência, onde os cientistas reconhecidos 
temem cair no esquecimento, enquanto os cientistas talentosos e desconhecidos temem nunca serem reconhecidos. Este aspecto, de acordo com Merton (1988), ocorre principalmente em contextos onde antes existiu uma relação professor-aluno, quando ambos são talentosos e concorrem na mesma área de conhecimento; pois o exaluno, obscurecido pelo efeito Mateus, passa a achar que seu exprofessor já foi mais brilhante, enquanto este acredita que pode vir a ser substituído pelo ex-pupilo. Isso seria o "efeito compensação" (em que alguns entram em declínio e outros começam a se sobressair), que funciona como uma espécie de mecanismo de controle para restringir a acumulação de vantagem na ciência.

A precoce "obsolescência" da produção científica em muitas áreas do conhecimento faz com que artigos científicos, livros, capítulos de livros e outras produções só sejam considerados em alguns baremas (de concursos, progressão na carreira, dentre outros) se forem publicados há menos de cinco anos, acirrando a concorrência existente na comunidade científica; pois a contínua e crescente produtividade dos pesquisadores tem se tornado cada vez mais determinante para o reconhecimento material e imaterial dos cientistas. Na década de 1960, no contexto americano, o estudo de Cole e Cole (1967) já apontava que um artigo com cinco ou menos anos de publicação tinha dezessete vezes mais chance de ser citado do que um artigo científico com mais de vinte anos.

Nessa conjuntura, há um número cada vez maior de artigos científicos publicados e uma crescente pressão para que os pesquisadores aumentem constantemente sua produção científica. Isso faz com que a grande maioria dos pesquisadores não consiga publicar no mesmo ritmo dos cientistas renomados e que seja humanamente impossível tomar conhecimento e ler tudo o que se publica em qualquer área do conhecimento, o que faz com que os cientistas desconhecidos tendam a permanecer anônimos e que seus trabalhos 
não sejam lidos, nem citados, apesar do sistema de recompensas da ciência exigir dos cientistas justamente o contrário para seu progresso sócio-científico. O desespero para manter-se no mundo acadêmico, apesar de não conseguir enquadrar-se neste padrão excludente, pode levar muitos pesquisadores a práticas como o plágio, a falsificação e a fabricação de dados. Ao tratar deste assunto, Merton (1988) diz que a propriedade intelectual no domínio científico sustenta-se por um código de lei implícito comum, consubstanciado na citação, e resulta no reconhecimento pelos pares. Ele reforça essa ideia ao afirmar que:

A própria forma de artigo científico, tal como evoluiu nos últimos três séculos, requer, normativamente, que os autores reconheçam nos ombros de quem eles se encontram, sejam eles os ombros de gigantes ou, como frequentemente é o caso, aqueles de homens e mulheres de ciência de dimensões aproximadamente médias para as espécies scientificus (MERTON, 1988, p. 227-228, grifo do autor).

Diante da necessidade de se sobressair, muitos cientistas migram para áreas do conhecimento correlatas e/ou para linhas de pesquisa que supostamente são menos concorridas no intuito de conseguirem reconhecimento científico. Segundo Ben-David (1960), isso é possível porque os cientistas possuem capacidade de generalização e são mais motivados para isso, pois intentam estabelecer-se no novo campo como inovadores. Todavia este novo campo institucionalmente mais promissor tende a ser cognitivamente inerte e o prestígio profissional pode vir às custas de estagnação intelectual, e não, às custas de uma grande descoberta ou inovação (MARCOVICH E SHINN, 2013; BEN-DAVID, 1960).

Outro aspecto digno de nota são os periódicos que só aceitam artigos científicos de doutores, bem como o crescente número de periódicos que condicionam a submissão de artigos científicos à condição de assinante ou que solicitam pagamento para submissão e 
publicação de artigos científicos. Em nosso entender, tais exigências reforçam o efeito Mateus, pois criam conflitos de interesse e barreiras monetárias ao excluir, antes mesmo de sua submissão, bons artigos provenientes de cientistas talentosos de instituições com pouco financiamento que não possuem condições financeiras de arcar com os custos da publicação. Sabemos que os periódicos científicos passam por duras avaliações nacionais e internacionais no intuito de atestar sua qualidade científica e que também sofrem com as implicações negativas do efeito Mateus, além de terem que arcar com uma série de custos relacionados ao seu funcionamento acadêmico e administrativo e de precisarem contar a com a boa vontade e a agilidade de seus pareceristas para se manterem competitivos no mundo acadêmico. Todavia acreditamos que cobrar taxas e estabelecer condições de ordem monetária no intuito de garantir esta manutenção não é o melhor caminho. O financiamento dos periódicos científicos pelas instituições nas quais estão sediados (universidades, institutos de pesquisa, conselhos e ordens de classe, dentre outros) seria uma alternativa mais inclusiva.

Soma-se a isso o fato de que o sistema de publicações norteamericano (que é o maior, o mais famoso, o mais citado e detentor do maior fator de impacto) ser bastante fechado e, em grande parte, de acesso restrito, monopolizado por editoras como a Elsevier; nas quais não é necessário apenas pagar altos valores para publicar, mas também para ter acesso aos artigos publicados. Argumenta-se que as despesas com os custos destes periódicos não são pagos diretamente pelos pesquisadores, e sim, pela Capes e pelas instituições de ensino e pesquisa (universidades e institutos de pesquisa); mas o custo global da assinatura de todas essas bases de dados não costuma ser baixo e poderia ser investido em mais pesquisas. Estes aspectos denotam que, embora Merton (1977a, p. 567) apregoe que "a ciência é pública, não 
privada", pelo menos no que concerne à publicação científica, ela tem se tornado cada vez mais privada.

O sistema brasileiro de publicação, no entanto, é em grande parte gratuito, inclusive no que concerne à disponibilidade de artigos científicos para leitura e download, mas não é igualmente valorizado, não possui o mesmo destaque internacional que o sistema norte-americano e costuma-se atribuir menor pontuação aos artigos publicados em periódicos brasileiros do que aos periódicos estrangeiros, cujo fator de impacto científico geralmente é maior do que o dos periódicos brasileiros.

Rodríguez (2009) resume as implicações negativas do efeito Mateus ao afirmar que ele provoca a redução ou anulação de benefícios de qualquer tipo para pessoas ou entidades que possuem menor valor diante de um determinado parâmetro considerado relevante, gerando casos de marginalização, pois elas passam a ser consideradas de forma diferente quando se percebe que elas se encontram nos últimos lugares de uma dada classificação. Além disso, frequentemente permanecem muito abaixo do esperado devido aos recursos com os quais contam e, em último extremo, são despojados do que possuem e entregam o que ainda têm, gerando uma distância entre os reconhecidos e desconhecidos afetados pelo efeito Mateus. Ainda nessa linha, Jarvie e Agassi (2011) criticam duramente o efeito Mateus ao classificá-lo como uma deformidade institucional, cuja noção de tirar vantagem, em uma primeira leitura, parece "uma exposição da corrupção que existe no coração da ciência emergente" (JARVIE E AGASSI, 2011, p. 59).

Sob a perspectiva de todas as suas implicações negativas apresentadas nesta seção, o efeito Mateus não é ético; pois contribui para a perpetuação, no âmbito da comunidade científica, dos preconceitos, das exclusões, das desigualdades, das iniquidades e das injustiças presentes na sociedade. 


\section{Reflexões Sobre as implicações Éticas do Efeito Mateus na CiÊnCia}

Ao longo da história da humanidade (inclusive no período da Segunda Guerra Mundial), em sua prática profissional, muitos cientistas abriram mão da ética e/ou a restringiram apenas ao seu caráter individual e subjetivo, facilitando suas próprias vidas e suas práticas profissionais ao considerar que a sua responsabilidade ética resumiase à apresentação dos resultados positivos ou negativos à comunidade científica, sem ponderar as consequências destes resultados para a sociedade, bem como que a ética deve ser considerada em todo o processo de pesquisa, a começar pela sua concepção/idealização (PEGORARO, 2002). Diante de tantas atrocidades cometidas em nome da ciência, é importante reforçar que, embora muitos ainda acreditem no contrário, a ciência não é neutra, nem autônoma e que, cada vez mais, será necessário que os cientistas prestem contas de suas pesquisas à sociedade. A existência de formas de controle social da ciência, como os Comitês de Ética em Pesquisa (CEP), é uma prova do crescimento desta tendência; já que, segundo Carvalho (2011), na atualidade, a cobrança para que os cientistas assumam a responsabilidade por suas pesquisas tem aumentado, pois eles costumam ser os primeiros a perceber as possibilidades tecnológicas do que investigam.

Cupani (1998) reforça essa tese de não neutralidade da ciência ao lembrar que é inconcebível um pesquisador que não tenha posições prévias, que não esteja comprometido com uma teoria, tradição profissional ou intelectual, ideologia ou que seja emocionalmente neutro. Morin (2007) corrobora este pensamento ao afirmar que a ciência é complexa e ambivalente, podendo ser, ao mesmo tempo, útil e nefasta e que muitos cientistas encontram-se cegos em relação aos problemas postos pelo conhecimento científico. Tal cegueira é criada pelo processo de cegamento inerente ao conhecimento objetivo; pois, de acordo com Carvalho (2011, p. 103), “a cultura científica é uma 
subcultura de uma cultura maior, e o cientista não se despe desta última quando trabalha em Ciência". Isso reforça o fato de que a comunidade científica faz parte da sociedade e, portanto, não pode ser considerada como algo a parte ou superior a ela.

Além disso, a própria necessidade de financiamento contribui para jogar por terra essa errônea ideia de neutralidade e autonomia da ciência; pois, conforme lembra Morin (2005), é predominantemente o Estado que financia, controla e desenvolve as instituições de pesquisa. Disso se depreende que, pelo menos no Brasil, mesmo os pesquisadores mais famosos são obrigados a compatibilizar o tema de suas pesquisas com o tema de interesse dos órgãos de fomento à pesquisa e que os interesses desses dois atores nem sempre estão atrelados às necessidades sociais.

Outro problema que pode ocorrer do âmbito do tema de pesquisa em países em desenvolvimento, como o Brasil, é a integração subordinada. Esta dá-se quando pesquisadores prestigiosos destes países encontram-se integrados em comunidades científicas internacionais e dedicam-se a pesquisas de interesse de países desenvolvidos, gerando uma tensão entre a relevância social da pesquisa e a visibilidade internacional no contexto da produção de conhecimento (KREIMER, 2006). A nosso ver, este aspecto é um claro exemplo do quão profunda pode ser a influência do efeito Mateus na ciência e sua consequência é o atraso do avanço do conhecimento científico dos países em desenvolvimento, principalmente no que concerne a temas de relevância social local.

Estes aspectos nos permitem afirmar que o conhecimento científico como um todo sofre influência do efeito Mateus, pois esse fenômeno faz com que percamos em capacidade de reflexão, com que grandes ideias possam ser perdidas, dificultando mais e melhores descobertas, pois grandes gênios podem nunca chegar a ser conhecidos. Isso nos leva a questionar: se a influência do efeito Mateus 
não existisse, o conhecimento científico poderia ter assumido diferentes direções? Os grandes nomes (expoentes) da ciência seriam outros? Não temos respostas para estas perguntas. O efeito Mateus é apenas um dos múltiplos fatores que influenciam o avanço do conhecimento científico; além disso, embora acreditamos que, para que um cientista seja beneficiado pelo efeito Mateus, é necessário alguma dose de sorte, esforço próprio e/ou ajuda de alguém interessado em favorecê-lo, não podemos reduzir o fenômeno do efeito Mateus a estas três simples causas. Pode haver muitas outras, as quais são difíceis de identificar e mensurar por se tratar de um fenômeno social e psicológico.

É provável que, ao longo da história do desenvolvimento científico, estas características do efeito Mateus tenham contribuído também para a perda de grandes talentos por preconceitos devido ao gênero, orientação sexual, condição financeira, etnia, religião, dentre outros aspectos. Tolhidos, impedidos de pesquisar ou usurpados de suas descobertas ou contribuições à ciência, estas pessoas simplesmente desapareceram e jamais serão resgatadas, pois a História as ignorou, reduzindo-as a uma inexistência forjada. Como consequência, temos hoje uma História predominantemente masculina e estéril de uma prolífica diversidade que poderia ter contribuído não apenas com criatividade, mas com outras formas de ver o mundo que poderiam ter resultado em importantes descobertas. $\mathrm{Na}$ atualidade, embora as minorias tenham conseguido, a custa de muita luta, se fazer ver, ainda há um longo caminho a percorrer, pois o preconceito, ainda que velado, continua existindo.

Neste contexto, precisamos ter em mente que devemos valorizar a qualidade da produção científica, independente de quão reconhecido é o seu autor ou de questões que podem dar vasão ao preconceito (tais como gênero, orientação sexual, etnia, religião ou condição financeira); pois o fato de um cientista ser reconhecido e/ ou ter características culturais, biológicas e socialmente desejáveis 
não significa que ele seja o melhor ou domine todo o saber de sua área do conhecimento científico. Um cientista desconhecido pode trazer importantes contribuições à ciência que podem jamais vir a ser conhecidas diante das várias dificuldades que ele pode encontrar para realizar sua pesquisa e publicá-la. Do que vale uma grande quantidade de publicações se estas não tiverem qualidade? Se não contribuírem para o desenvolvimento da Ciência? Se não forem eticamente aceitáveis e possuírem relevância social?

Soma-se a isso o fato de que, para ser prolífico em publicações científicas, os cientistas têm que ser, essencialmente, escritores ou contar com pupilos que o sejam, pois os seres humanos têm diferentes habilidades e nem todas as pessoas têm aptidão para escrever, o que faz com que a escrita que, para alguns é um prazer, seja, para outros, motivo de grande dificuldade.

Além disso, háalgumasáreas doconhecimento, comoas ciências biológicas, em que o desenvolvimento das pesquisas pode ser lento e laborioso, dependendo não apenas de talento, mas de infraestrutura e equipamentos de tecnologia de ponta. Isso significa que, nas ciências naturais, a produtividade científica sofre a interferência de uma série de fatores que fogem ao controle do cientista e que, ser produtivo nestas áreas, envolve, em grande parte, possuir um bom financiamento, uma excelente infraestrutura física no laboratório, ter excelentes contatos com instituições de ponta (inclusive internacionais), estar envolvido em várias pesquisas ao mesmo tempo e contar com um bom número de pupilos talentosos.

Disso se depreende que, ao privilegiar a quantidade da produção científica em detrimento da qualidade, acabamos favorecendo a perpetuação do efeito Mateus. Esta necessidade que o cientista atual tem de desempenhar múltiplos papeis no âmbito da comunidade científica nos conduz a Ben-David (1974) que afirma que o papel social do cientista envolve uma hibridização de papeis, pois 
o cientista é, ao mesmo tempo, pesquisador e professor universitário. Nós acrescentaríamos que, na atualidade, exige-se que ele seja também um escritor, o que torna ainda mais atual a afirmação de BenDavid (1974, p. 69) de que o papel científico emergiu "como um papel singular, com possibilidades e obrigações específicas".

Embora Morin (2005) relate que a ciência "clássica", ainda predominante na atualidade, elimina de seu meio toda a competência ética, Garrafa (1999) alerta para a crescente necessidade de se considerar o papel do cientista e sua responsabilidade ética, os quais devem ser avaliados pelo seu exercício profissional e pelas consequências sociais advindas dessa prática. Disso se depreende que o cientista não deve ficar indiferente aos desdobramentos sociais de suas pesquisas; pois "se a ciência como tal não pode ser ética ou moralmente qualificada, pode sê-la, no entanto, a utilização que dela se faça, os interesses a que serve e as consequências sociais da sua aplicação" (GARRAFA, 1999, s.p.), o que significa que será cada vez mais necessário que a sociedade exija que os cientistas assumam a responsabilidade ético-científica por suas pesquisas (CARVALHO, 2011) e que a democratização e o controle social da ciência podem contribuir para a realização deste intento (GARRAFA, 1999).

No contexto atual, em que a relevância social das pesquisas torna-se cada vez mais necessária, deixar de pensar nas consequências de sua pesquisa (sejam elas sociais, ambientais, biomédicas, etc.)éescusar-sedesua responsabilidadeético-profissional. Daí a importância de que a ética perpasse todo e qualquer tipo de formação profissional e que os códigos de ética profissionais sejam bem elaborados no intuito de promover a ética em favor da vida, da justiça, do meio ambiente, da equidade, dos direitos e oportunidades iguais, independente da prática profissional a ser exercida. Assumir essa postura poderá contribuir para promover a equidade social não apenas na ciência, mas também na sociedade, uma vez que o efeito 
Mateus também é um fenômeno social. Poderá também contribuir para a redução das implicações econômicas e políticas do efeito Mateus para que possamos caminhar em direção à justiça distributiva, a qual depende de atitudes político-econômicas.

Assim, no intuito de atenuar as implicações negativas do efeito Mateus, Rodríguez (2009) propõe alternativas sociais (reconhecimento cultural de minorias marginalizadas, redistribuição da riqueza, focalização dos gastos públicos nas pessoas mais necessitadas, políticas sociais fundadas na equidade) e científicas (criação de um sistema participativo de reconhecimento ao invés do modelo piramidal existente, prêmios de consolação, reconhecimentos locais, criação de procedimentos mais justos de avaliação da qualidade das pesquisas, fortalecimentos dos sistemas nacionais de publicação ao atribuir-lhes fator de impacto equivalente ao americano - ISI Mundial - e a realização de revisão por pares de artigos científicos realizadas a cegas).

Concordamos com Rodríguez (2009) e, embora não haja critérios universalmente aceitos de mérito científico, propomos também os seguintes aspectos concernentes ao âmbito científico brasileiro: criação de um sistema de financiamento equitativo à pesquisa e às instituições de ensino e/ou pesquisa, estímulo à avaliação por pares de artigos científicos duplo cega (o avaliador não conhece o avaliado e o avaliado não conhece o avaliador), alteração dos baremas que subvalorizam os bolsistas voluntários para atribuir-lhes valor igual a dos bolsistas remunerados, reconhecimento do esforço dos alunos talentosos independente de serem tardios ou precoces e de possuírem ou não bolsa de estudos, equiparação nacional do sistema brasileiro de publicação ao norte-americano por meio do estabelecimento de pontuação igual para ambos nos baremas e sistemas de reconhecimento do mérito científico nacionais, maior valorização de bases de dados para pesquisa como o SciELO e de portais de periódicos nacionais que publicam e disponibilizam seus artigos gratuitamente, criação 
de critérios mais justos de avaliação da produção científica dos pesquisadores, focando na qualidade e não na quantidade.

Do contrário, o efeito Mateus será cada vez mais reforçado, a estrutura de classes na ciência continuará cada vez mais excludente e continuaremos numa competição cada vez mais acirrada, numa luta cada vez mais irracional que nos remota a uma espécie de seleção natural darwiniana, onde só os mais reconhecidos sobreviverão e que nada tem de natural, pois é cada vez mais mercadológica.

\section{CONSIDERAÇões FINAIS}

Embora tenha sido enunciado por Merton no início da segunda metade do século XX, o efeito Mateus é um fenômeno bastante atual; uma vez que, na atualidade, acirram-se as desigualdades tanto na sociedade quanto na ciência, onde a competição por reconhecimento é cada vez mais pronunciada.

Apesar disso, na conjuntura atual, também há uma crescente necessidade de que as pesquisas demonstrem sua relevância social, fazendo com que o cientista seja conclamado a assumir sua responsabilidade ético-científica pelas pesquisas que realiza. Isso exige que a sua postura ética não se centre apenas na apresentação dos resultados da pesquisa e/ou em seu processo de execução, mas que envolva também suas relações com outros cientistas e com a sociedade; pois, embora se saiba que a ciência não é capaz de resolver todos os problemas da humanidade, ela precisa contribuir para que eles, um dia, sejam solucionados ou, pelo menos, indicar possíveis caminhos a se seguir.

Assim, diante dos inúmeros benefícios e malefícios proporcionados pela ciência à humanidade, já está mais do que claro seu caráter complexo e ambivalente, que pode ser bom ou mal, favorecer a justiça e a inclusão ou a injustiça e a exclusão. Isso significa 
que a ciência tem duas faces e que precisamos sempre ter cuidado para, irrefletidamente, não optarmos pela face da injustiça e da exclusão, reforçando preconceitos e discrepâncias na geração e avanço do conhecimento científico e, assim, indiretamente perpetuarmos o efeito Mateus.

Disso se depreende que, por ser uma disfunção social, que reforça o preconceito velado que perpassa e influencia as estruturas sociais e científicas e privilegia o individualismo, o efeito Mateus demanda que os cientistas se autossubmetam contínua e humildemente a uma autoavaliação crítica de sua conduta profissional, bem como que favoreçam atitudes mais éticas e inclusivas que nos permitam construir, num futuro próximo, uma ciência eticamente responsável que seja de todos e para todos, e não, uma ciência cega de suas responsabilidades e consequências. Enfim, para se possamos construir uma ciência inclusiva, em que o efeito Mateus seja esquecido e não promova o esquecimento.

\section{REFERÊNCIAS}

ÁVILA, Patrícia. A Distribuição do Capital Científico: Diversidade Interna e Permeabilidade Externa no Campo Científico. Sociologia - Problemas e Práticas, no 25, 1997, p. 9-49.

BEN-DAVID, Joseph. Roles and Innovations in Medicine. American Journal of Sociology, vol. 65, nº 6, mai/1960, p. 557-568.

BEN-DAVID, Joseph. O Papel do Cientista na Sociedade. São Paulo: Pioneira, Editora da Universidade de São Paulo, 1974, p.37-51; 69-76.

BEN-DAVID, Joseph; Sullivan, Teresa. Sociology of Science. Annual Review of Sociology, vol. 1, 1975, p. 203-222.

BUNGE, Mario. Ética y Ciencia. 3 ed. Buenos Aires: Ediciones Siglo Viente, 1972, p.11-65.

BUNGE, Mario. El efecto San Mateo. Polis, vol. 2, 2002, p.1-5. 
CAPES - Portal de Periódicos CAPES. Coleções. 2014. Disponível em: < http://www. periodicos.capes.gov.br/?option=com_pcollection\&mn=70\&smn=79\&cid=81>. Acesso em 16 jun 2014.

CLARK, Ronald W. The Life and Work of J. B. S. Haldane. New York: Coward-McCann, 1969, p.138-156.

CARVALHO, Washington Luiz Pacheco de. Elementos sociais para a compreensão do prestígio científico e de seus riscos. TEA - Tecné, Episteme y Didaxis, nº 30, 2011, p. $91-110$.

COLE, Sthepen; COLE; Jonathan R. Scientific output and recognition: a study in the operation of the reward system in science. American Sociological Review, vol. 32, $\mathrm{n}^{\mathrm{o}} 3,1967$, p. 377-390.

CUPANI, Alberto. A Propósito do "Ethos" da Ciência. Episteme, vol. 3, n.6, Porto Alegre, 1998, p. 16-38.

DAVYT, Amilcar; VELHO, Léa. A avaliação da ciência e a revisão por pares: passado e presente. Como será o futuro? Hist. cienc. saúde-Manguinhos. vol. 7, no 1, Rio de Janeiro, mar-jun/2000. Disponível em: < http://www.scielo.br/scielo. php? script=sci_arttext\&pid=S0104-59702000000200005\&lng=en\&nrm=iso $>$. Acesso: 24 jun. 2014. http://dx.doi.org/10.1590/S0104-59702000000200005. [Artigo em formato html, sem número de páginas.]

GARRAFA, Volnei. Bioética e ciência: Até onde avançar sem agredir. Revista CEJ, vol. 3, n. 7, jan-abr/1999. Disponível em: < http://www2.cjf.jus.br/ojs2/index.php/ revcej/article/ view/183/345>. Acesso em 24 jun. 2014. [Artigo em formato html, sem número de páginas.]

HAGSTROM, Warren O. O Controle Social dos Cientistas. In: DEUS, Jorge Dias (org). A Crítica da Ciência. Rio de Janeiro: Zahar Editores, 1974, p. 81-105.

HAYASHI, Maria Cristina Piumbato Innocentini; CABRERO, Rodrigo de Castro; COSTA, Maria da Piedade Resende da; HAYASHI, Carlos Roberto Massao. Indicadores da participação feminina em Ciência e Tecnologia. TransInformação, vol. 19, nº 2, Campinas, mai-ago/2007, p.169-187.

JARVIE, Ian; AGASSI, Joseph. Por uma sociologia crítica da ciência. Sociologias, ano 13, no 26, Porto Alegre, jan-abr/ 2011, p. 44-83.

KREIMER, Pablo. ¿Dependientes o integrados? La ciencia latinoamericana y la nueva división internacional del trabajo. Nómadas, vol 24, Colômbia, 2006, p.199212. 
KROPF, Simone Petraglia; LIMA, Nísia Trindade. Os valores e a prática institucional da ciência: as concepções de Robert Merton e Thomas Kuhn. História, Ciências, Saúde Manguinhos, vol. 3, nov/1998-fev/1999, p. 565-581.

LATOUR, Bruno. Ciência em ação: como seguir cientistas e engenheiros sociedade afora. 2 ed. São Paulo: UNESP, 2011, p.1-155.

LIMA, Nísia Trindade. Valores Sociais e Atividades Científicas: Um Retorno à Agenda de Robert Merton. In: PORTOCARRERO, Vera (Org.). Filosofia, história e sociologia das ciências I: abordagens contemporâneas. Rio de Janeiro: Editora FIOCRUZ, 1994, p. 151-173.

MacDOWELL, João Augusto A.A. Ética Política: Urgência e Limites. Síntese Nova Fase, vol. 48, 1990, p. 07-34.

MARCOVICH, Anne; SHINN, Terry. Posfácio. Robert K. Merton, fundador da Sociologia da Ciência: comentários, insights e críticas. In: MARCOVICH, Anne; SHINN, Terry. Ensaios de Sociologia da Ciência. São Paulo: Editora 34, 2013, p.253272.

MERTON, Robert K. Science and the Social Order. Philosophy of Science, vol. 5, no 3, jul/1938, p. 321-337.

MERTON, Robert K. El efecto Mateo en la ciencia. In: MERTON, Robert King. La Sociologia de la Ciencia 2. Madrid: Alianza Editorial SA, 1977a, cap. 20, p. 554-578.

MERTON, Robert K. El estimulo puritano a la ciencia. In: MERTON, Rober King. La Sociologia de la Ciencia 2. Madrid: Alianza Editorial SA, 1977b, cap.11, p. 309-338.

MERTON, Robert K. Os Imperativos Institucionais da Ciência. In: DEUS, Jorge Dias (Org). A Crítica da Ciência. Rio de Janeiro: Zahar Editores, 1974, p. 37-52.

MERTON, Robert K. O Efeito Mateus na Ciência II. A Vantagem Cumulativa e o Simbolismo da Propriedade Intelectual. 1988. In: MARCOVICH, Anne; SHINN, Terry. Ensaios de Sociologia da Ciência. São Paulo: Editora 34, 2013, p. 199-231.

MORIN, Edgar. Ciência com Consciência. 82 ed. Rio de Janeiro: Bertrand Brasil, 2005, p.15-172.

MORIN, Edgar. O Método 6: Ética. 3 ed. Porto Alegre: Sulina, 2007, p. 69-79.

OLIVEIRA, Fátima. Uma Visão Feminista Sobre os Megaprojetos da Genética Humana (PGH e PDGH). Revista Bioética, vol. 5, no2, Brasília, nov/2009, p. 1-8.

PEGORARO, Olinto A. Ética e Bioética. Da Subsistência à Existência. Petrópolis, RJ: Vozes, 2002, p.21-73. 
RODRÍGUEZ, Jorge Jiménez. El Efecto Mateo: Un Concepto Psicológico. Papeles del Psicólogo, vol. 30, nº 2, may-ago/2009, p. 145-154.

REZENDE, Joffre Marcondes de. A vida breve de alguns personagens famosos da história da medicina. In: REZENDE, Joffre Marcondes de. À sombra do plátano: crônicas de história da medicina. São Paulo: Editora Unifesp, 2009, p. 273-280.

ROCHA, Ednéia Silva Santos; SANTOS, Jean Carlos Ferreira dos; SILVA, Marcia Regina da; Rodrigues, Vanessa. Ética e Integridade na Produção do Conhecimento Científico. Alexandría: Revista de Ciencias de la Información, ano 6, no 9, ene-dic/2012, p. 58-76.

ROSSITER, Margaret W. The Matthew Matilda Effect in Science. Social Studies of Science, vol. 23, nº 2, mai/1993, p. 325-341. 